\title{
Reduction of gastric cancer proliferation and invasion by miR- 15a mediated suppression of Bmi-1 translation
}

\author{
Changping Wu $\mathbf{W}^{1,2,3, *}$, Xiao Zheng ${ }^{2,3,4, *}$, Xiaodong $\mathrm{Li}^{1,2,3,4, *}$, Andrew Fesler ${ }^{4}$, Wenwei \\ $\mathrm{Hu}^{1,2,3}$, Lujun Chen ${ }^{2,3}$, Bin $\mathrm{Xu}^{2,3}$, Qi Wang ${ }^{2,3}$, Anthony Tong ${ }^{5}$, Stephanie Burke ${ }^{4}$, \\ Jingfang $\mathrm{Ju}^{4}$, Jingting Jiang ${ }^{2,3}$ \\ ${ }^{1}$ Department of Oncology, The Third Affiliated Hospital of Soochow University, Changzhou, China \\ ${ }^{2}$ Department of Biological Treatment, The Third Affiliated Hospital of Soochow University, Changzhou, China \\ 3 Jiangsu Engineering Research Center for Tumor Immunotherapy, Changzhou, China \\ ${ }^{4}$ Translational Research Laboratory, Department of Pathology, Stony Brook University, Stony Brook, NY, USA \\ ${ }^{5}$ BioGenex Inc., Fremont, CA, USA \\ *These authors have contributed equally to this work \\ Correspondence to: Jingting Jiang, e-mail: jiangjingting@suda.edu.cn \\ Jingfang Ju, e-mail: jingfang.ju@stonybrookmedicine.edu \\ Keywords: miR-15a, gastric cancer, Bmi-1, survival \\ Received: June 30, $2015 \quad$ Accepted: January 12, $2016 \quad$ Published: February 15, 2016
}

\begin{abstract}
B-cell specific moloney leukemia virus insertion site 1 (Bmi-1) gene plays important roles in gastric cancer, but the epigenetic regulatory mechanism by microRNA (miRNA) and the functional significance of Bmi-1 inhibition in gastric cancer remains elusive. In this study, we systematically investigated the functional roles of miRNA mediated Bmi-1 suppression in gastric cancer. Our results show that the expression of miR-15a is significantly reduced in gastric cancer and the protein expression levels of Bmi-1 are inversely correlated with miR-15a $(P=0.034)$ in gastric cancer patient samples. Functional studies revealed that ectopic expression of $\mathbf{m i R}-$ 15a decreased Bmi-1 in gastric cancer cell lines with reduced proliferation and tumor invasion. High levels of Bmi-1 in gastric cancer patients are significantly associated with better overall survival $(P=0.024)$ based on the Kaplan-Meier survival analysis.
\end{abstract}

\section{INTRODUCTION}

Gastric cancer is the fifth most common malignancy globally and the third leading cause of cancer-related deaths $[1,2]$. Despite the treatment progress and research efforts in gastric cancer, the outcome of patients with stage IV disease remains disappointing, with a 5-year overall survival rate of $4 \%[3]$.

Gastric cancer is a genetic disease and multiple factors are involved in the multi-step processes of gastric cancer development $[4,5]$. The majority of gastric cancers are associated with bacterium Helicobacter pylori ( $H$. Pylori) and Epstein-Barr virus (EBV) [6]. The molecular and clinical characteristics are quite complex with both histological and aetiological heterogeneity. Based on The Cancer Genome Atlas (TCGA) analysis, it was proposed that gastric cancer can be divided into 4 unique subtypes [7]. The importance of epigenetic alterations in gastric cancer development and progression has only recently been appreciated [8]. One crucial aspect of epigenetic regulations is the involvement of non-coding miRNAs in gastric cancer development and progression [9].

miRNAs are non-protein-coding small RNAs with length between 19 and 25 nucleotides cleaved from 70 - to 100- nucleotide hairpin pre-miRNA precursors [10]. miRNAs post-transcriptionally regulate protein expression of many target genes by interacting with the 3'-UTR region of the mRNA transcripts. miRNAs have pivotal functions in various biological processes including cellular differentiation, proliferation and apoptosis [1114]. miRNAs have great potential as cancer biomarkers because of their superior stability, tissue-specificity and unique expression patterns in cancer cells $[15,16]$. Expression profiling analysis has discovered a number of miRNAs deregulated in human malignancies $[17,18]$.

miRNAs have been identified to be crucial in tumorigenesis by playing either oncogenic or tumor suppressive roles in gastric cancer [19-23]. A number of studies have identified miRNAs that play significant roles in gastric cancer [24-30]. Our group is particularly interested in 
the roles of miRNAs in regulating epithelial to mesenchymal transition (EMT) in gastric cancer. Gastric epithelial cell tumor transformation is rather complex with both genetic and epigenetic involvement. Previous studies have identified several key miRNAs (miR-15a, miR-16, miR-194 and miR200c) involved in EMT and tumor progression [31-33]. Among them, miR-15a was identified as a tumor suppressor by promoting apoptosis and inhibiting cell proliferation and downregulation of miR-15a predicts a poor survival outcome $[34,35]$. Like miR-15a, down-regulation of miR-16 has also been observed to be a poor prognostic indicator $[35,36]$. miR200c has been linked with tumor progression and resistance via down-regulation of Bmi-1 in various cancers [33, 37].

One common theme is that Bmi-1 is a key target for miR-15a, miR-16, and miR-200c based on several different tumor types $[31,33,38]$. Bmi-1 is a member of the polycomb group, which functions as a transcriptional repressor and presents high expression in many tumors, in most cases, indicating a poor prognosis $[38,39]$. Several lines of evidence suggest that Bmi-1 blocks cell senescence and proliferation $[40,41]$, and the Bmi-1 gene is also associated with tumor invasion and metastasis [42]. Aberrant expression of Bmi1 has been detected in several human cancers including lymphoma, acute myeloid leukemia, colorectal carcinoma, liver carcinoma, non-small cell lung cancer, breast carcinoma, prostate cancer, head and neck squamous cell carcinoma, medulloblastoma, and glioblastoma [40, 42-48]. Bmi-1 has been identified as a predictor of the response to therapy and survival in various tumors [49-51]. The miRNA mediated Bmi-1 expression and functional significance in gastric cancer remained elusive.

In this study, we systemically investigated the functional and clinical significance of miR-15a, miR-16, and miR-200c in gastric cancer. Among these, miR-15a is the most significantly down regulated miRNAs in gastric cancer. The expression of Bmi-1 is inversely correlated with the expression of miR-15a. Ectopically expression of miR-15a reduced gastric cancer cell growth and invasion. The expression of Bmi-1 is significantly correlated with gastric cancer patient survival.

\section{RESULTS}

\section{Patient baseline characteristics}

Table 1 summarizes the patient clinicalpathological characteristics of 352 primary gastric cancer specimens. There are 5 with stage I, 78 with stage II, 240 with stage III and 29 with stage IV gastric tumor tissues on the high density tissue microarray. Stage III samples represent $68 \%$ of all samples. Of note, there is a lack of clinical information on several patients and they have been secluded from the statistical analysis. The survival analysis revealed that the gastric cancer patients survive better with higher expression levels of Bmi-1, and correlated with smaller tumor size $(<5 \mathrm{~cm})$, better pathological differentiation (I-II), less lymph node metastases $(\leq 70 \%$ or earlier $\mathrm{N}$ stages), earlier T stages, non-metastatic disease (M0), earlier UICC stages (Table 2). The expression of Bmi-1 is significantly different in stage I-II vs. stage III-IV patients (Table 3).

\section{Differential expression of miRNAs expression in gastric cancer}

The expression of miRNAs (miR-15a, miR-16, and miR-200c) was quantified in 21 paired normal and gastric tumor specimens. Among these, miR-15a was significantly $(P=0.0239)$ reduced in gastric cancer tissues compared to the adjacent normal controls (Figure 1A) while no significant difference in miR-16 (Figure 1B) and miR200c (Figure 1C) were found.

\section{Bmi-1 is a direct target of miR-15a in gastric cancer cell lines}

To evaluate whether the expression of Bmi-1 is regulated by miR-15a in gastric cancer, the gastric cancer cell lines AGS and SNU-5 were transfected with 100 $\mathrm{nM}$ of miR-15a and negative control. The Bmi-1 protein level was quantified by Western immunoblot analysis 3 days after transfection. Our results show that we have successfully transfected miR-15a in AGS (Figure 2A) and SNU-5 (Figure 2B) based on qRT-PCR analysis. The expression of target protein Bmi-1 was significantly decreased in both AGS and SNU-5 cell lines quantified by the Western immunoblot analysis (Figure 2C) and quantified (Figure 2D-2E). There are three predicted and previous validated binding sites of miR-15a at the 3'-UTR region of Bmi-1 mRNA (Figure 2F). We have constructed a luciferase reporter system to demonstrate the direct interaction of Bmi-1 binding sites with miR-15a. Our results show that luciferase activity was significantly reduced by miR-15a in both AGS (Figure $2 \mathrm{G}$ ) and SNU-5 (Figure 2H) gastric cancer cells.

\section{The expression of Bmi-1 is inversely correlated with miR-15a in gastric tumor tissues}

The expression of Bmi-1 was quantified by IHC from 21 gastric tumor tissues. The expression of miR15 a was quantified by qRT-PCR analysis from total RNA isolated from the same set of gastric tumor tissues. The representative Bmi-1 expression ranging from negative, moderate, and high is shown in Figure 3A. The positive rate of miR-15a is about $16 \%$ of the 21 cases. The protein expression of Bmi-1 and miR-15a RNA levels was inversely correlated $\left(P=0.034, \mathrm{R}^{2}=0.22, \mathrm{r}=-0.48\right)$ based on two-tailed Spearman correlation in the gastric cancer patient samples (Figure 3B). In addition, we performed in situ hybridization of miR-15a in gastric tumor tissues and the results are consistent with qRT-PCR analysis that elevated miR-15a staining is associated with reduced expression level of Bmi-1 by IHC (Figure 3C-3D). 
Table 1: Correlation between patient clinicopathological characteristics and Bmi-1 expression

\begin{tabular}{|c|c|c|c|c|c|c|c|}
\hline \multirow{3}{*}{ Characteristics } & \multicolumn{4}{|c|}{ Bmi-1 expression } & \multirow{2}{*}{\multicolumn{2}{|c|}{ Total }} & \multirow{3}{*}{$P$} \\
\hline & \multicolumn{2}{|c|}{ Lower } & \multicolumn{2}{|c|}{ Higher } & & & \\
\hline & No. & $\%$ & No. & $\%$ & No. & $\%$ & \\
\hline Gender & & & & & & & 0.220 \\
\hline Male & 173 & 65.3 & 63 & 72.4 & 236 & 67.0 & \\
\hline Female & 92 & 34.7 & 24 & 27.6 & 116 & 33.0 & \\
\hline Age, years & & & & & & & 0.157 \\
\hline$\leq 60$ & 120 & 45.5 & 32 & 21.1 & 152 & 43.3 & \\
\hline$>60$ & 144 & 54.5 & 55 & 27.6 & 199 & 56.7 & \\
\hline Tumor site & & & & & & & 0.338 \\
\hline Cardia & 32 & 12.1 & 14 & 30.4 & 46 & 13.1 & \\
\hline Body & 72 & 27.2 & 22 & 23.4 & 94 & 26.7 & \\
\hline Pylorus & 126 & 47.5 & 45 & 26.3 & 171 & 48.6 & \\
\hline Unknown & 35 & 13.2 & 6 & 14.6 & 41 & 11.6 & \\
\hline Tumor size \# & & & & & & & 0.469 \\
\hline$<5 \mathrm{~cm}$ & 107 & 41.6 & 32 & 37.2 & 139 & 40.5 & \\
\hline$\geq 5 \mathrm{~cm}$ & 150 & 58.4 & 54 & 62.8 & 204 & 59.5 & \\
\hline Tumor shape & & & & & & & 0.481 \\
\hline Protrude & 6 & 3.5 & 0 & 0 & 6 & 2.5 & \\
\hline Ulcerative & 44 & 25.6 & 17 & 25.4 & 61 & 25.5 & \\
\hline Infiltratively ulcerative & 93 & 54.1 & 39 & 58.2 & 132 & 55.2 & \\
\hline Diffuse infiltrative & 17 & 9.9 & 6 & 9.0 & 23 & 9.6 & \\
\hline Superficial & 9 & 5.2 & 2 & 3.0 & 11 & 4.6 & \\
\hline Colloid & 3 & 1.7 & 3 & 4.5 & 6 & 2.5 & \\
\hline Pathological differentiation & & & & & & & 0.187 \\
\hline I & 3 & 1.1 & 2 & 2.3 & 5 & 1.4 & \\
\hline II & 55 & 20.8 & 23 & 26.4 & 78 & 22.2 & \\
\hline III & 181 & 68.3 & 59 & 67.8 & 240 & 68.2 & \\
\hline IV & 26 & 9.8 & 3 & 3.4 & 29 & 8.2 & \\
\hline Positive rate of lymph node & & & & & & & 0.580 \\
\hline$\leq 70 \%$ & 191 & 73.0 & 55 & 76.4 & 182 & 74.0 & \\
\hline$>70 \%$ & 77 & 27.0 & 17 & 23.6 & 64 & 26.0 & \\
\hline Tumor invasion & & & & & & & 0.092 \\
\hline $\mathrm{T} 1$ & 16 & 6.3 & 5 & 6.0 & 21 & 6.2 & \\
\hline $\mathrm{T} 2$ & 17 & 6.6 & 12 & 14.5 & 29 & 8.6 & \\
\hline $\mathrm{T} 3$ & 177 & 69.1 & 57 & 68.7 & 234 & 69.0 & \\
\hline $\mathrm{T} 4$ & 46 & 18.0 & 9 & 10.8 & 55 & 16.2 & \\
\hline Lymph node metastasis & & & & & & & $\begin{array}{c}0.394 \\
\text { (Continued) }\end{array}$ \\
\hline
\end{tabular}




\begin{tabular}{|c|c|c|c|c|c|c|c|}
\hline \multirow{3}{*}{ Characteristics } & \multicolumn{4}{|c|}{ Bmi-1 expression } & \multirow{2}{*}{\multicolumn{2}{|c|}{ Total }} & \multirow{3}{*}{$P$} \\
\hline & \multicolumn{2}{|c|}{ Lower } & \multicolumn{2}{|c|}{ Higher } & & & \\
\hline & No. & $\%$ & No. & $\%$ & No. & $\%$ & \\
\hline N0 & 55 & 20.9 & 22 & 25.3 & 77 & 22.0 & \\
\hline N1 & 34 & 12.9 & 16 & 18.4 & 50 & 14.3 & \\
\hline $\mathrm{N} 2$ & 78 & 29.7 & 21 & 24.1 & 99 & 28.3 & \\
\hline N3 & 96 & 36.5 & 28 & 32.2 & 124 & 35.4 & \\
\hline Distant metastasis & & & & & & & 0.907 \\
\hline M0 & 252 & 95.1 & 83 & 95.4 & 335 & 95.2 & \\
\hline M1 & 13 & 4.9 & 4 & 4.6 & 17 & 4.8 & \\
\hline UICC staging ( $7^{\text {th }}$ edition) & & & & & & & 0.535 \\
\hline Stage I & 12 & 4.7 & 4 & 4.8 & 16 & 4.7 & \\
\hline Stage II & 74 & 28.9 & 31 & 37.3 & 105 & 31.0 & \\
\hline Stage III & 157 & 61.3 & 44 & 53.0 & 201 & 59.3 & \\
\hline Stage IV & 13 & 5.1 & 4 & 4.8 & 17 & 5.0 & \\
\hline
\end{tabular}

\# Tumor size was defined as the largest diameter of the tumor mass.

Table 2: Univariate analysis for survival

\begin{tabular}{|c|c|c|c|}
\hline Characteristics & Survival time $(95 \% \mathrm{CI})$ & Log-rank $\chi^{2}$ & $P$ \\
\hline Gender & & 1.447 & 0.229 \\
\hline Male & $31.933(22.956-40.910)$ & & \\
\hline Female & $26.233(22.035-30.432)$ & & \\
\hline Age, years & & 0.651 & 0.420 \\
\hline$\leq 60$ & $29.100(17.826-40.374)$ & & \\
\hline$>60$ & $27.867(19.884-35.850)$ & & \\
\hline Tumor site & & 0.603 & 0.740 \\
\hline Cardia & $43.767(33.309-54.225)$ & & \\
\hline Body & $26.233(13.621-38.845)$ & & \\
\hline Pylorus & $31.367(21.071-41.662)$ & & \\
\hline Tumor size & & 30.469 & $<0.001$ \\
\hline$<5 \mathrm{~cm}$ & $50.067(38.385-61.748)$ & & \\
\hline$\geq 5 \mathrm{~cm}$ & $19.333(14.970-23.697)$ & & \\
\hline Tumor shape & & 4.031 & 0.133 \\
\hline Ulcerative & $26.233(4.483-47.984)$ & & \\
\hline Infiltratively ulcerative & $34.867(22.310-47.424)$ & & \\
\hline Diffuse infiltrative & $25.033(19.294-30.772)$ & & \\
\hline Pathological differentiation & & 12.351 & $<0.001$ \\
\hline I - II & $52.767(30.414-75.119)$ & & \\
\hline III - IV & $25.233(21.304-29.163)$ & & \\
\hline
\end{tabular}

(Continued) 


\begin{tabular}{|c|c|c|c|}
\hline Characteristics & Survival time $(95 \% \mathrm{CI})$ & Log-rank $\chi^{2}$ & $\boldsymbol{P}$ \\
\hline Positive rate of lymph node & & 54.122 & $<0.001$ \\
\hline$\leq 70 \%$ & $44.133(36.234-52.033)$ & & \\
\hline$>70 \%$ & $16.100(11.585-20.615)$ & & \\
\hline Tumor invasion & & 50.022 & $<0.001$ \\
\hline $\mathrm{T} 1$ & - & & \\
\hline $\mathrm{T} 2$ & $58.167(35.007-81.326)$ & & \\
\hline $\mathrm{T} 3$ & $24.967(21.593-28.341)$ & & \\
\hline $\mathrm{T} 4$ & $17.967(13.000-22.934)$ & & \\
\hline Lymph node metastasis & & 79.468 & $<0.001$ \\
\hline N0 & $65.600(52.589-78.611)$ & & \\
\hline N1 & $40.033(30.136-49.931)$ & & \\
\hline $\mathrm{N} 2$ & $26.600(17.252-35.948)$ & & \\
\hline N3 & $17.500(14.860-20.140)$ & & \\
\hline Distant metastasis & & 9.254 & 0.002 \\
\hline M0 & $29.267(21.773-36.760)$ & & \\
\hline M1 & $17.033(14.400-19.667)$ & & \\
\hline UICC staging ( $7^{\text {th }}$ edition $)$ & & 68.366 & $<0.001$ \\
\hline Stage I & - & & \\
\hline Stage II & $47.867(40.589-55.144)$ & & \\
\hline Stage III & $20.167(16.991-23.342)$ & & \\
\hline Stage IV & $17.033(14.400-19.667)$ & & \\
\hline Bmi-1 expression & & 5.091 & 0.024 \\
\hline Lower & $24.533(20.791-28.275)$ & & \\
\hline Higher & $43.533(30.311-56.756)$ & & \\
\hline
\end{tabular}

Table 3: Different Bmi-1 expression level between gastric cancer patients with stage I-II and stage III-IV

\begin{tabular}{lcccc}
\hline UICC stage & No. & $\begin{array}{c}\text { Bmi-1 expression } \\
\text { level (min-max) }\end{array}$ & Z & $\boldsymbol{P}$ \\
\hline Stage I-II & 129 & $90(0-290)$ & 2.304 & 0.021 \\
Stage III-IV & 224 & $80(0-300)$ & & \\
Stage II & 111 & $90(0-290)$ & 2.109 & 0.035 \\
Stage III & 206 & $80(0-300)$ & & \\
\hline
\end{tabular}

miR-15a suppressed the proliferation of gastric cancer cells via downregulation of Bmi-1

It has been demonstrated that Bmi-1 can regulate the proliferation and clonal growth of tumor cells in a number of malignant tumors [40]. Therefore, we evaluated the role of Bmi-1 in mediating the proliferation of a gastric cancer cell lines. We found that when miR- 15a was transfected into gastric cancer cell lines AGS and SNU-5, it caused a significant reduction in cell proliferation as compared to blank control (Figure 4A4B). To ensure that such inhibition of gastric cancer cell proliferation is directly due to the reduction of Bmi-1, we were able to reverse the miR-15a suppressed proliferation by restoration of Bmi-1 expression (Figure 4A-4B). 


\section{miR-15a suppressed gastric cancer invasion}

Bmi-1regulates EMT and promotes cancer cell invasion [53], therefore we reasoned that miR-15a may have an impact on gastric cancer invasion. We used a transwell system containing an extracellular matrix (ECM) layer to study the change in invasion activity. We demonstrated that overexpression of miR-15a reduced cell number invading through the ECM by nearly $50 \%$ when compared to negative control (Figure 4C-4F).

\section{Association between Bmi-1 expression and patients' overall survival time and survival rates}

We next analyzed the relationship between Bmi-1 expression and gastric cancer patients' survival based on
352 clinical samples. Based on the Kaplan-Meier survival analysis, cumulative survival curves were calculated, and differences in survival time were assessed with the log-rank test. The median survival time for gastric cancer patients demonstrating high expression of Bmi1 was significantly $(P<0.024)$ shorter $(24.5$ months $)$ in comparison to patients with low Bmi-1 expression (43.5 months) (Figure 5A). In addition, among lymph node positive gastric cancer patients, high levels of Bmi-1 patients had a significant $(P=0.007)$ better survival rate than that of patients with low levels of Bmi-1 (Figure 5B).

\section{DISCUSSION}

In this study, we systemically investigated the functional and clinical significance of miR-15a

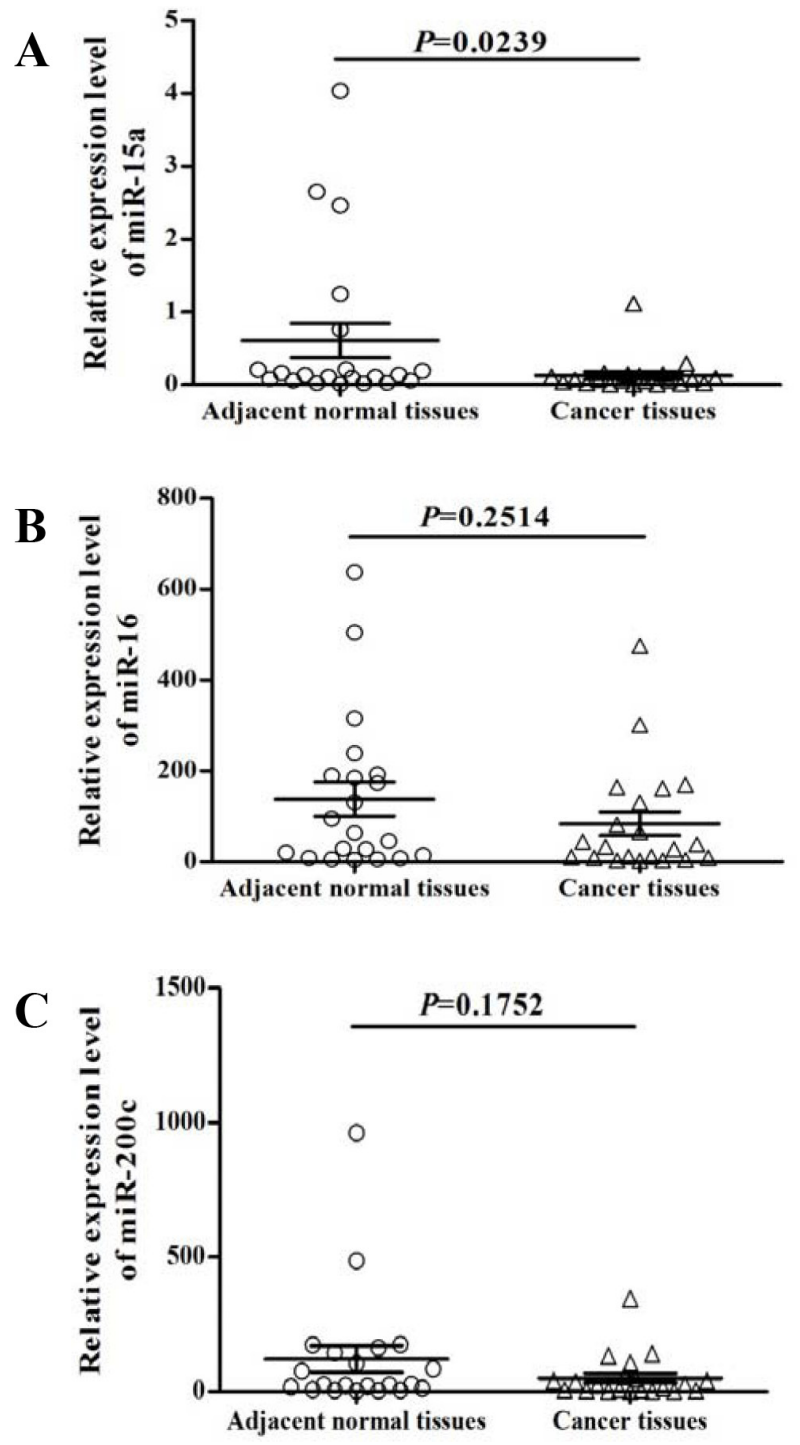

Figure 1: Expression analysis of miR-15a, miR-16, and miR-200c in gastric cancer. The expression levels of miR-15a A., miR-16 B. and miR-200c C. were quantified by qRT-PCR analysis from 21 paired normal and gastric tumor tissues. miR-15a was significantly $(P=0.0239)$ decreased in gastric cancer $(\mathrm{A})$. 
in gastric cancer using in vitro and clinical samples. One of the important targets of miR-15a is Bmi-1. We quantified the expression levels of several miRNAs that were previously reported to suppress Bmi-1 protein expression in other tumor types using 25 gastric tumor specimens and the corresponding non-neoplastic gastric mucosa using qRT-PCR analysis. By comparing the expression profiles, we found a significant
A

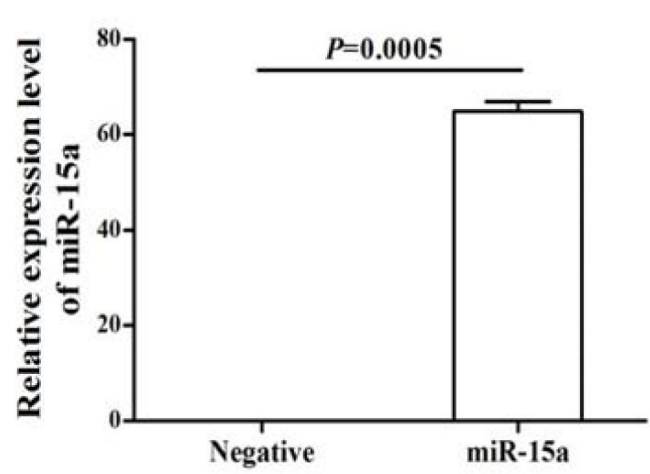

C

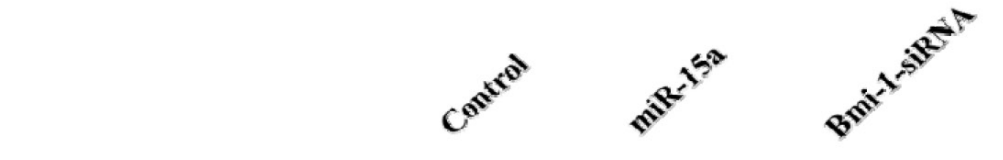

kDa

AGS

Bmi-1

B

SNU-5

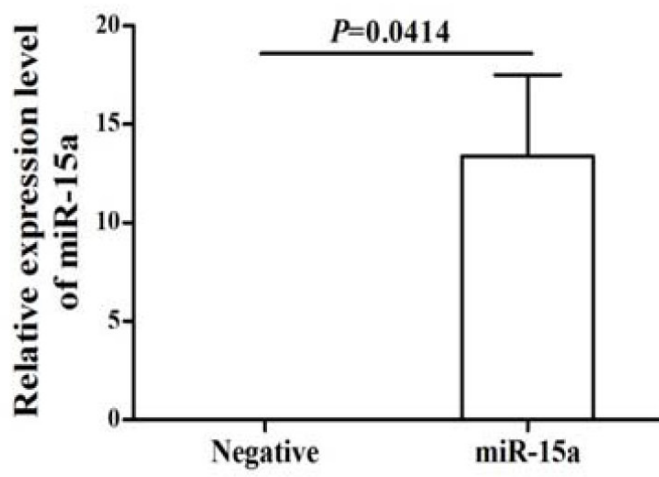

$-41$

GAPDH

$-\mathbf{3 7}$

Bmi-1

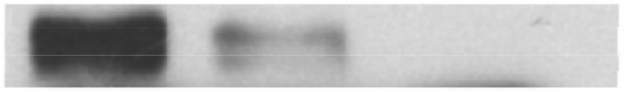

$-41$

SNU-5

GAPDH

D

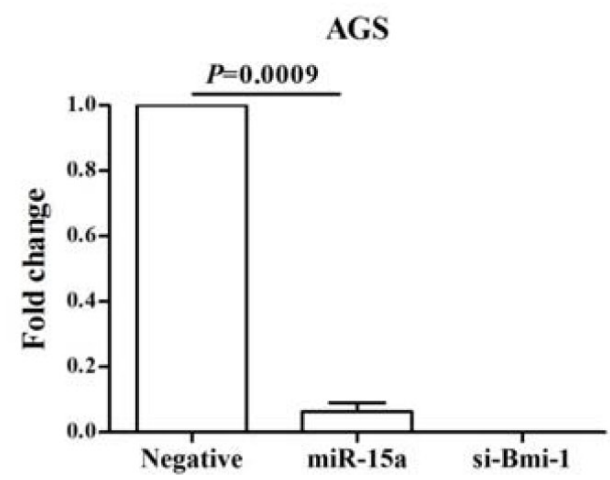

$\mathbf{E}$

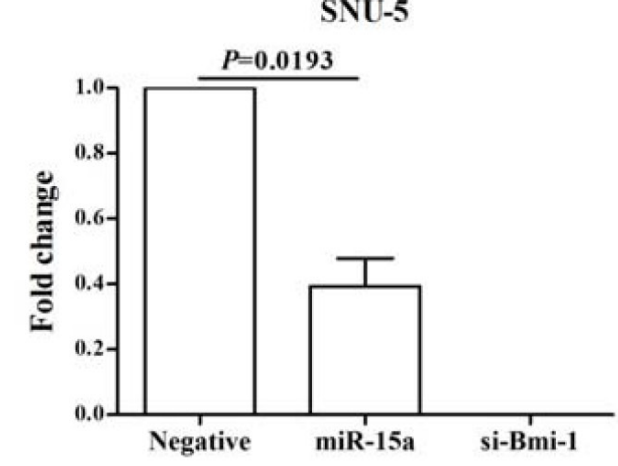

Figure 2: Regulation of Bmi-1 expression by miR-15a in gastric cancer cell lines. qRT-PCR analysis of ectopically transfected miR-15a in AGS A. and SNU-5 B. gastric cancer cell lines. miR-15a suppresses Bmi-1 protein expression in AGS and SNU-5 cell lines by Western blotting C. Quantitative analysis of miR-15a in suppressing Bmi-1 expression by Western immunoblot analysis in AGS D. and SNU-5 E. cell lines. The control is a representative value of two different negative controls as both miRNA and siRNA control did not show any effect. miR-15a directly interacts with the 3'-UTR region of Bmi-1. (Continued) 


\section{$\mathbf{F}$}

\begin{tabular}{|l|l|l|}
\hline \multicolumn{1}{|c|}{ Luciferase } & Bmi-1 3'-UTR \\
\hline miRNA & 3' guGUUUGGUAAUACACGACGAu 5' \\
Target 5' & 571 $\quad$ ttTA-TAC ---- TTC-TCTG-TTGCTa 3' \\
\hline
\end{tabular}

miRNA 3' guguuugGUA-AUACACGACGAu 5'

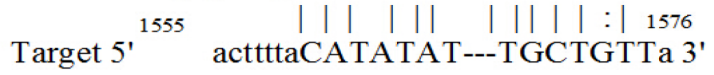

miRNA $3^{\prime}$ guguuuGGUAAUA--CACGACGAu 5'
$\begin{gathered}{ }^{1659} \quad||||||:||||:||: \mid 1682 \\ \text { Target } 5^{\prime} \text { acagtcCCATTGTAAGTGTTGTTt 3' }\end{gathered}$

G

AGS

H SNU-5
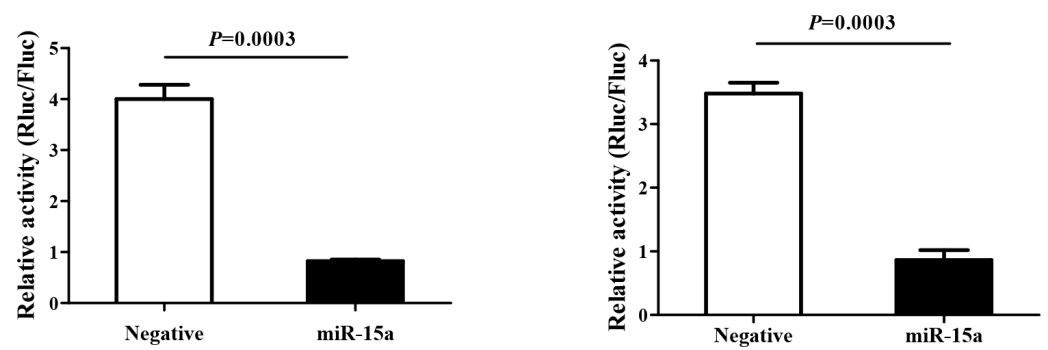

Figure 2: (Continued) F. to suppress the expression of luciferase reporter protein in AGS G. and SUN-5 H. gastric cancer cell lines.

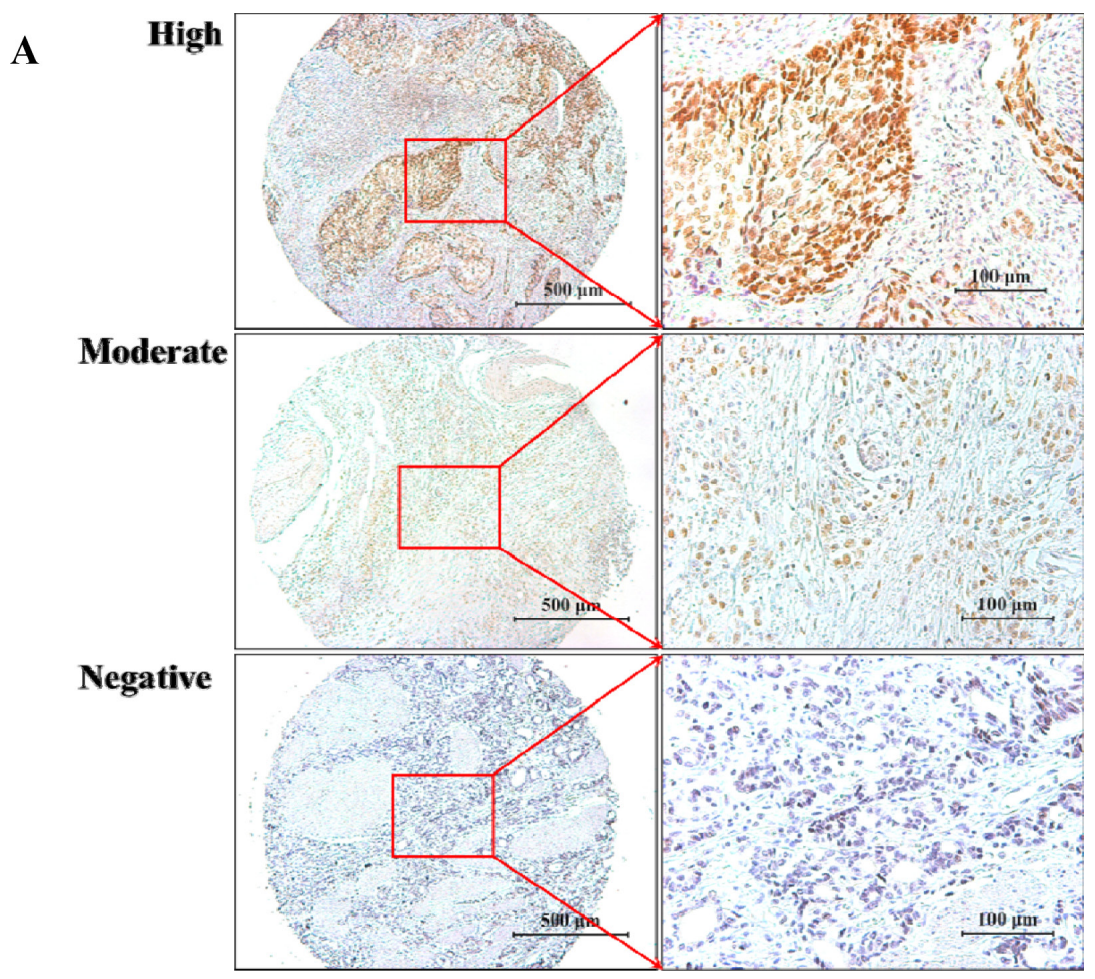

Figure 3: The expression level of miR-15a is inversely correlated with Bmi-1 expression in gastric tumor tissues. Immunohistochemical analysis of Bmi-1 in gastric cancer tissues showing representative images of high, moderate and negative staining A. The expression levels of Bmi-1 is significantly $(n=21, P=0.034, \mathrm{R} 2=0.22, \mathrm{r}=-0.48)$ inversely correlated with miR-15a expression based on two-tailed Spearman correlation analysis. The positive rate of miR-15a is 16\%. (Continued) 

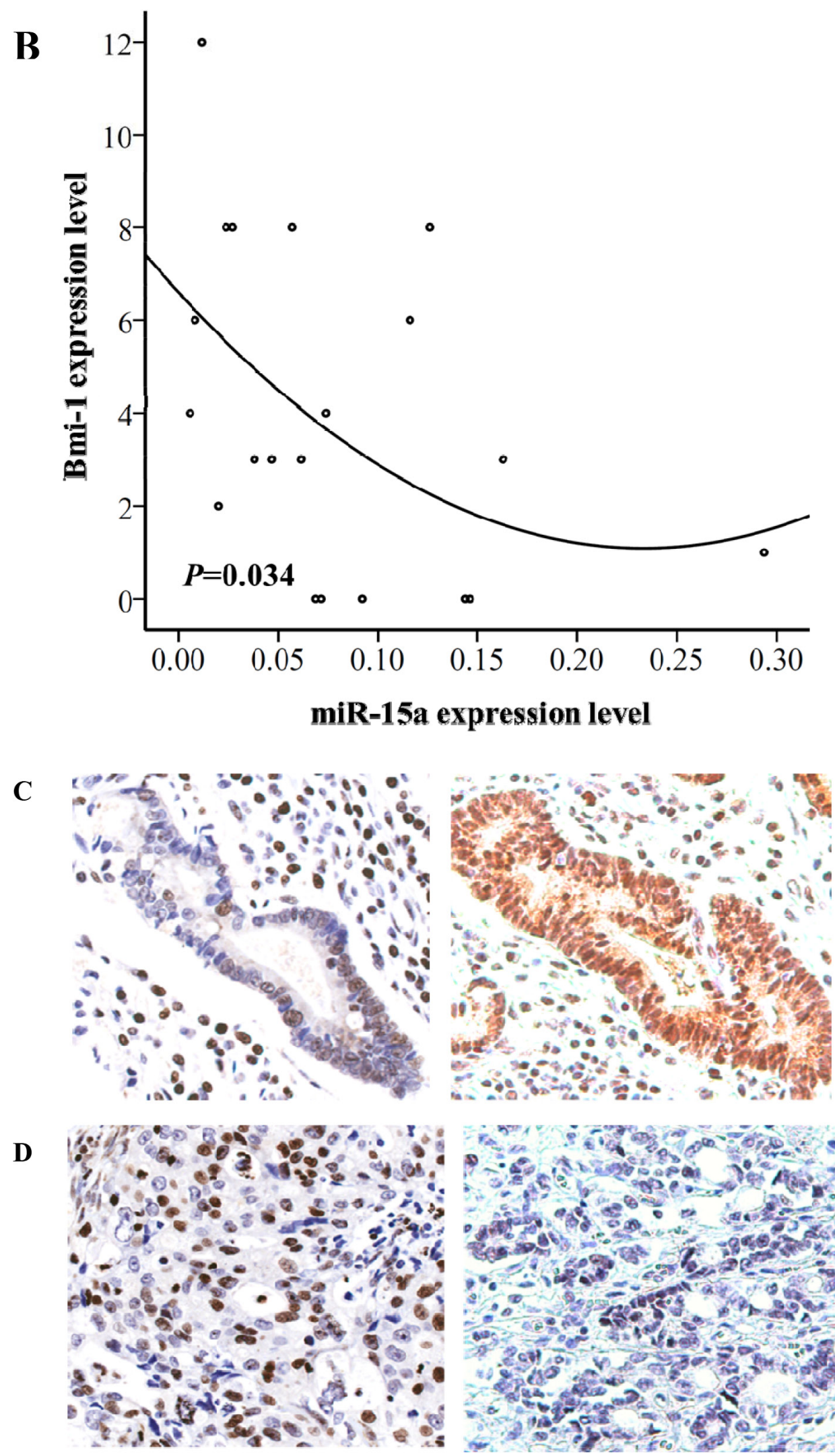

Figure 3: (Continued) B. Inverse expression of miR-15a and Bmi-1 protein levels via in situ hybridization analysis of miR-15a and Bmi-1 expression quantified by $\mathrm{IHC}$ analysis $\mathbf{C}-\mathbf{D}$. in gastric tumor tissues. 
A

AGS

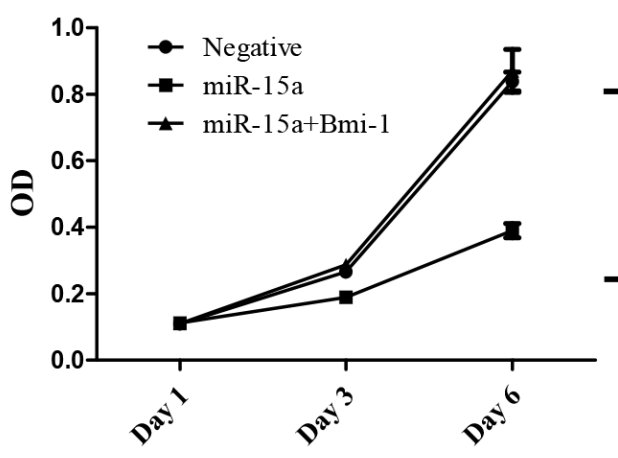

B

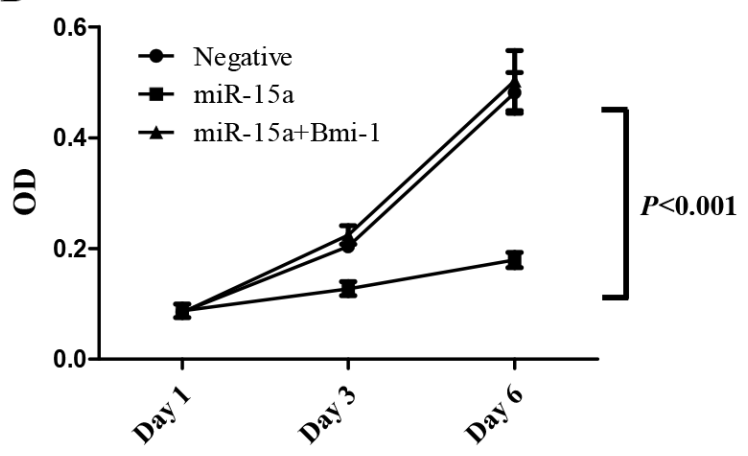

C

AGS
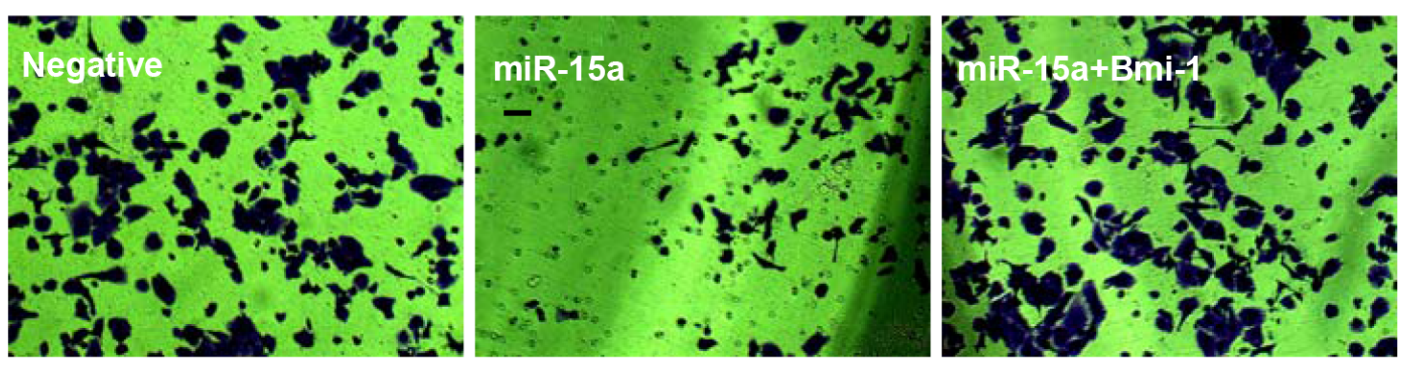

D

SNU-5
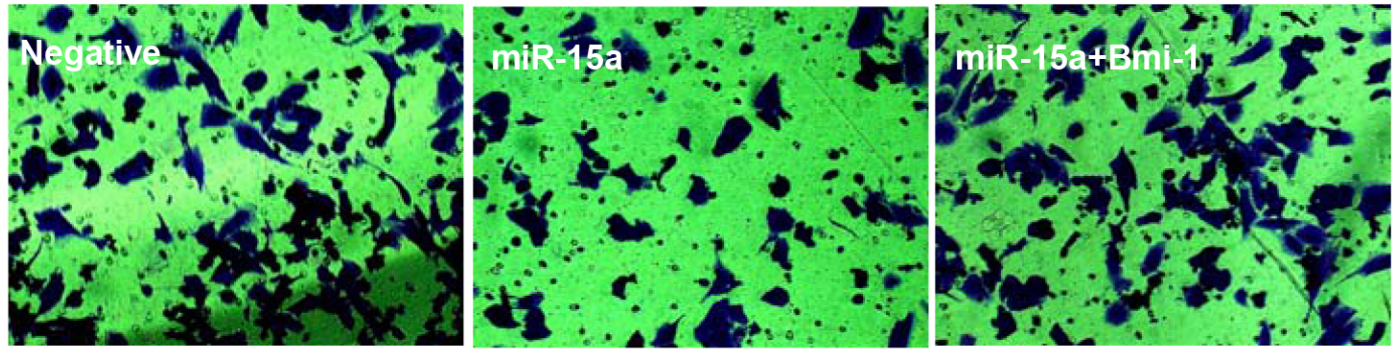

E

F

AGS

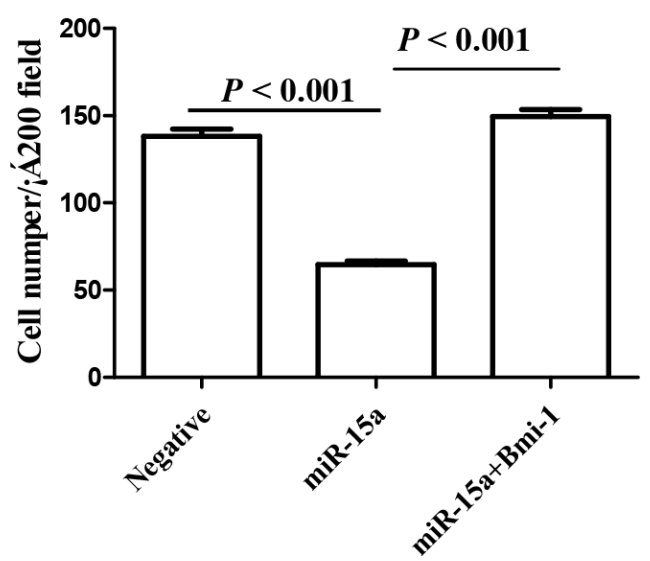

SNU-5

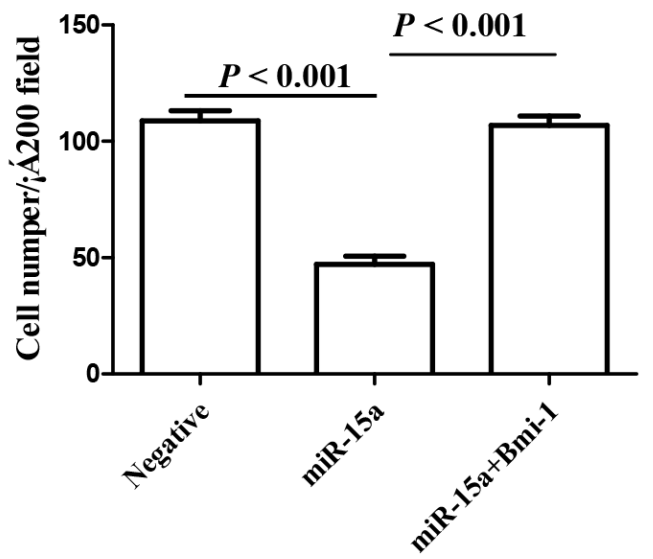

Figure 4: Ectopic expression of miR-15a suppressed gastric cancer cell proliferation in AGS A. and SNU-5 B. gastric cancer cell lines 3 and 6 days after transfection. Ectopic expression of miR-15a suppressed gastric cancer cell invasion in AGS C, E. and SNU-5 D, F. gastric cancer cell lines. The inhibition effect can be reversed specifically by restoration of the Bmi-1 expression. 

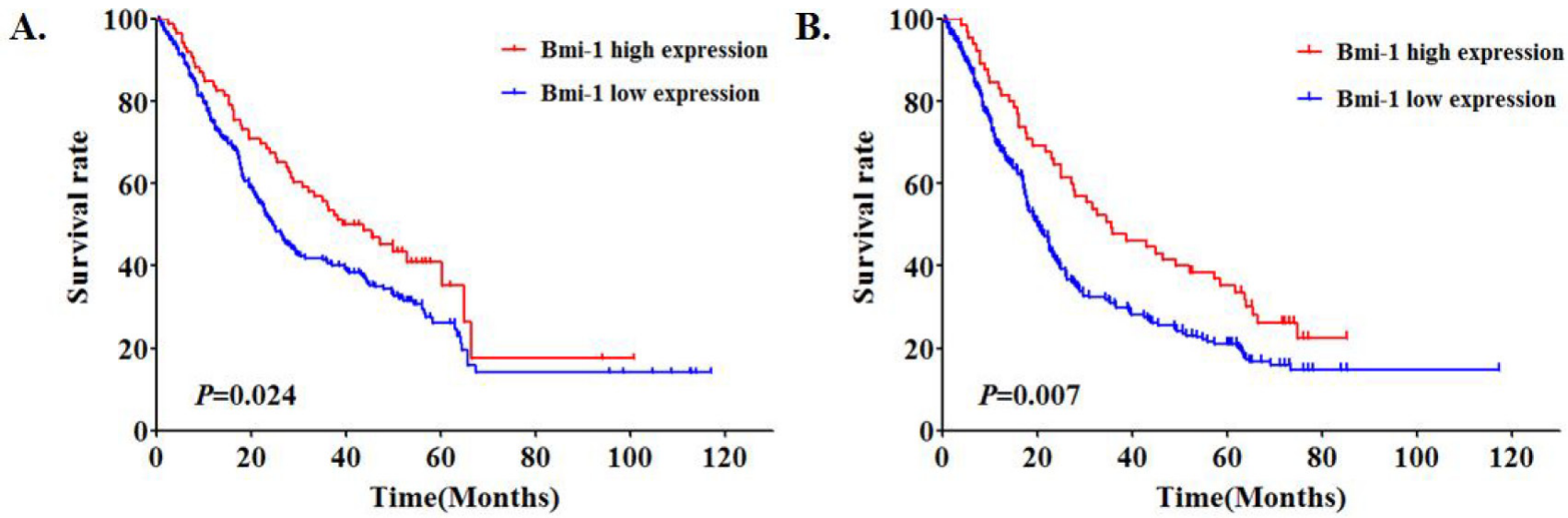

Figure 5: Bmi-1 expression levels are significantly associated with gastric cancer patient survival based on Kaplan-Meier survival analysis in all patients $(P=0.024) \mathbf{A}$. and in lymph node positive patients $(P=0.007) \mathbf{B}$.

downregulation of miR-15a in the majority of gastric cancer tissues (Figure 1A), while there is no significant changes in the expression of miR-16 or miR-200c. We further confirmed that Bmi-1 was a direct target of miR$15 \mathrm{a}$ using immunohistochemical staining, qRT-PCR, luciferase reporter assay and Western blot analysis (Figure 2A-2H).

It has been reported that miR-15a inhibits cell proliferation in pancreatic ductal adenocarcinoma and ovarian cancer by downregulating Bmi- 1 expression [31, 38]. Our results support the important roles of Bmi-1 played in tumor invasion and growth in gastric cancer with a unique regulatory mechanism by miR-15a.

However, despite the functional significance of Bmi-1 in regulating proliferation and progression, the clinical impact of Bmi-1 in gastric cancer is quite complex as patients with high levels of Bmi-1 had better survival than patients with low Bmi-1 expression (Figure 5A-5B). This is based on a 352 large gastric cancer patient cohort. It has been reported in breast cancer that patients with high levels of Bmi-1 had a more favorable outcome than patients with low expression of Bmi-1 [54]. This is different from the findings in other gastrointestinal tumor types such as colorectal cancer and pancreatic cancer, where patients with low Bmi-1 expression had a better survival outcome $[38,55]$. This discrepancy might be explained by the complex function of polycomb protein Bmi-1. Bmi-1 functions as a double edged sword. It has been reported that leukemic stem cells lacking Bmi-1 do not proliferate [56]. As a transcriptional repressor, Bmi-1 also regulates cell proliferation and senescence through the ink4a locus [40]. As a result, gastric tumor cells that have low levels of Bmi-1 will be slowly proliferating and insensitive to chemotherapy which target rapid proliferative cells. In contrast, gastric cancer cells with high levels of Bmi-1 proliferate rapidly, making them sensitive to chemotherapy. This is consistent with our observation that knock-down Bmi-1 expression by miR-15a reduces gastric cancer cell proliferation (Figure 4A-4B). Our results suggest that there is a good possibility that a relative large number of patients retained a significantly high enough level of miR-15a to suppress the expression of Bmi-1 in gastric cancer. The favorable outcome of gastric cancer patients with high levels of Bmi-1 may be due to the fact that these gastric tumor cells are highly sensitive to chemotherapy treatment while patients with low Bmi-1 level are less sensitive. Another possibility is that high levels of Bmi-1 are crucial in blocking MET process of advance stage gastric tumor in vivo. Such phenotypes warrant further investigation.

In summary, we discovered that the expression of Bmi-1 is regulated by miR-15a in gastric cancer. The prognostic significance of Bmi-1 in gastric cancer supports future multi-center large cohort studies.

\section{MATERIALS AND METHODS}

\section{Patients and samples}

A total of 21 formalin-fixed paraffin-embedded (FFPE) gastric cancer tissues and the paired normal tissues were obtained from the Third Affiliated Hospital of Soochow University, China. Written patient consent was obtained and the study was approved by the Ethics Committee of the Third Affiliated Hospital of Soochow University. Human gastric cancer high density tissue microarray from Shanghai Outdo Biotech Co. LTD. contains 352 primary tumor specimens with clinical follow up information included for the analysis of Bmi-1 expression and survival analysis. The patient baseline characteristics are listed in Table 1. Of note, some of the patient's clinical information is not available and they were secluded from the statistical analysis. 


\section{Cell lines and culture conditions}

The gastric cancer cell lines AGS and SNU-5 were obtained from American Type Culture Collection (ATCC), and were maintained in F-12K supplemented with $10 \%$ fetal bovine serum and IMDM supplemented with $20 \%$ fetal bovine serum medium respectively (Life Technologies Inc.).

\section{miRNA transfection}

Gastric cancer cell lines AGS and SNU-5 were cultured in appropriate medium for $24 \mathrm{~h}$ before the transfection experiment. Using Lipofectamine ${ }^{\mathrm{TM}} 2000$ (Life Technologies Inc.), the cell line was transfected with $100 \mathrm{nM}$ of miR-15a or negative control. The Bmi-1 protein expression was quantified $72 \mathrm{~h}$ post-transfection by Western blotting.

\section{RNA and protein isolation}

Total RNA from the transfected gastric cancer cell lines as well as frozen gastric cancer samples was extracted using TRIzol reagent, and total protein was isolated from the transfected cell lines using RIPA buffer (Sigma-Aldrich). The RNA and protein extractions were stored at $-80{ }^{\circ} \mathrm{C}$.

\section{Western immunoblot analysis for Bmi-1 expression}

Seventy-two hours after transfection, cells were lysed with RIPA buffer (Sigma-Aldrich), and Western immunoblot analysis was performed using standard procedures. The primary antibodies used for the analysis were mouse anti-human Bmi-1 antibody (1:2000; Cell Signaling), mouse anti-human GAPDH antibody (1:2000, Santa Cruz Biotechnology, Santa Cruz, CA, USA). Horseradish peroxidase-conjugated (HRP) antibodies against mouse (1:5000; Bio-Rad, Hercules, CA, USA) or against rabbit (1:5000; Cell Signaling Technology) were used as the secondary antibodies. HRP activity was detected with SuperSignal West Pico Chemiluminescent Substrate (Thermo Fisher Scientific) and visualized using autoradiography film. Quantification was performed using ImageJ software.

\section{Expression analysis of miRNAs by real-time qPCR}

FFPE gastric tumor tissues were deparaffinized, hydrated, and digested with proteinase K (SigmaAldrich). Subsequently, total RNA was isolated using the TRIzol reagent (Life Technologies Inc.). Total RNA was also isolated from the clinical specimens with the TRIzol-based approach. The candidate miRNAs (miR15a, miR-16 and miR-200c) shown previously to regulate Bmi-1 were quantified using real-time qRT-PCR TaqMan
microRNA analysis in both normal and gastric cancer samples.

The miRNA-specific primers and the internal control RNU44 gene primers were purchased from Life Technologies. cDNA synthesis was performed by the High Capacity cDNA Synthesis Kit (Life Technologies Inc.) with miRNA-specific primers. Real-time qRT-PCR was carried out on an Applied Biosystems 7500 RealTime PCR machine with miRNA-specific primers by TaqMan Gene Expression Assay (Life Technologies Inc.). Expression level of miR-15a was calculated by the $\Delta \Delta \mathrm{Ct}$ method based on the internal control RNU44, normalized to the control group and plotted as relative quantification.

\section{Expression analysis of miR-15a by in situ hybridization}

The expression analysis of miR-15a in FFPE gastric tumor tissues were quantified by in situ hybridization performed by BioGenex Inc. (Fremont, CA). In brief, 5'-fluorescein-labeled LNA-modified DNA oligonucleotides against the full length of the miR-15a were used for ISH analysis [52]. Probes with mismatch mutations were used as control. An antibody sandwich detection of miRNA probe using antifluorescein primary antibody followed by a tyramide signal amplification reaction, in which HRP conjugated to secondary antibody activates the tyramine moiety of a fluorochrome-conjugated substrate resulting in a covalent attachment of this fluorescent reagent to proteins in the vicinity of the miRNA probe. The signals were detected by the BioGenex's imaging detection system.

\section{Cell proliferation assay}

Twenty-four hours after transfection, cells were seeded in 96-well plates at a density of 2000 cells per well. The cell proliferation assay was performed on days 1,3 and 6 by incubating $10 \mathrm{ml}$ WST-1 (Roche Applied Science) in the culture medium for $1 \mathrm{~h}$ and reading the absorbance at 450 and $630 \mathrm{~nm}$. The cell proliferation rate was calculated by subtracting the absorbance at $450 \mathrm{~nm}$ from the absorbance at $630 \mathrm{~nm}$.

Experiments for the cell proliferation assay were performed at least three times.

\section{Immunohistochemistry (IHC)}

IHC analysis of Bmi-1 was performed using a standard streptavidin-biotin-peroxidase complex method. For antigen retrieval, paraffin tissue slides were microwave-treated for $2 \mathrm{~h}$ and boiled in a $0.01 \mathrm{M}$ citrate buffer $(\mathrm{PH}=6.0)$ for $18 \mathrm{~min}$. The slides were the treated with $0.5 \%$ Triton for $20 \mathrm{~min}$ to break the cell membranes. 
The slides were incubated with mouse mAb against human Bmi-1 (Millipore, 1:200 dilution) overnight at 4 ${ }^{\circ} \mathrm{C}$ and then incubated with goat anti-mouse

IgG for $2 \mathrm{~h}$. Normal pancreatic tissue slides were acquired by superseding the primary antibody with normal rabbit or mouse IgG.

\section{Statistical analysis}

All data were analyzed with SPSS statistical software (SPSS Standard version 13.0, SPSS Inc.). For univariate survival analysis, we analyzed all gastric cancer patients by Kaplan-Meier analysis. The log-rank test was used to compare different

survival curves. The association between Bmi-1 protein expression and the clinicopathological features of the gastric cancer patients was assessed with the Chi-square test. $P<0.05$ was considered statistically significant. All statistical analyses were performed with Graphpad Prism (version 6.01) software (La Jolla, CA, USA). The statistical significance between two groups was determined by Wilcoxon matched-pairs signed-rank test for clinical samples and by Student's unpaired t-test for all other experiments. The statistical significance among several groups was analyzed by Kruskal-Wallis oneway analysis of variance test with Dunn's multiple comparisons test. Data were expressed as mean \pm S.E.M.

\section{ACKNOWLEDGMENTS}

This study was supported by National Natural Science Foundation of China (No. 81301960, 81171653), The National Key Technology R\&D Program (No. 2015BAI12B12) and National Clinical Research Center for Cancer, Natural Science Foundation of Jiangsu Province (BK2011246, BK2011247), The Project of Six Batch of Major Talent Summit (BRA2010037), Jiangsu Key Laboratory of Medical Science and Laboratory Medicine (JSKLM-2014-003), Society development plans, Department of Science and Technology Changzhou (CJ20112020, CZ20110024, CS20102020), and The Innovative Talents Training Project of Changzhou Health Bureau. This study was also supported in part by the National Cancer Institute R01CA155019 (J. Ju), R33CA147966 (J. Ju).

\section{CONFLICTS OF INTEREST}

None.

\section{REFERENCES}

1. Torre LA, Bray F, Siegel RL, Ferlay J, Lortet-Tieulent J and Jemal A. Global cancer statistics, 2012. CA Cancer J Clin. 2015; 65:87-108.
2. Ferlay J, Soerjomataram I, Dikshit R, Eser S, Mathers C, Rebelo M, Parkin DM, Forman D and Bray F. Cancer incidence and mortality worldwide: sources, methods and major patterns in GLOBOCAN 2012. International journal of cancer. 2015; 136:E359-386.

3. Thrumurthy SG, Chaudry MA, Chau I and Allum W. Does surgery have a role in managing incurable gastric cancer? Nature reviews Clinical oncology. 2015; 12:676-682.

4. Khalighinejad N, Hariri H, Behnamfar O, Yousefi A and Momeni A. Adenoviral gene therapy in gastric cancer: a review. World J Gastroenterol. 2008; 14:180-184.

5. Tajima Y, Yamazaki K, Makino R, Nishino N, Aoki S, Kato M, Morohara K, Kaetsu T and Kusano M. Gastric and intestinal phenotypic marker expression in early differentiated-type tumors of the stomach: clinicopathologic significance and genetic background. Clin Cancer Res. 2006; 12:6469-6479.

6. Figueiredo C, Costa S, Karameris A and Machado JC. Pathogenesis of Gastric Cancer. Helicobacter. 2015; 20 Suppl 1:30-35.

7. Cancer Genome Atlas Research N. Comprehensive molecular characterization of gastric adenocarcinoma. Nature. 2014; 513:202-209.

8. Wu WK, Lee CW, Cho CH, Fan D, Wu K, Yu J and Sung JJ. MicroRNA dysregulation in gastric cancer: a new player enters the game. Oncogene. 2010; 29:5761-5771.

9. Link A, Kupcinskas J, Wex T and Malfertheiner P. Macrorole of microRNA in gastric cancer. Dig Dis. 2012; 30:255-267.

10. Zeng Y. Principles of micro-RNA production and maturation. Oncogene. 2006; 25:6156-6162.

11. Lee YS and Dutta A. MicroRNAs in cancer. Annu Rev Pathol. 2009; 4:199-227.

12. Ambros $\mathrm{V}$. The functions of animal microRNAs. Nature. 2004; 431:350-355.

13. Farh KK, Grimson A, Jan C, Lewis BP, Johnston WK, Lim LP, Burge CB and Bartel DP. The widespread impact of mammalian MicroRNAs on mRNA repression and evolution. Science. 2005; 310:1817-1821.

14. Bartel DP. MicroRNAs: genomics, biogenesis, mechanism, and function. Cell. 2004; 116:281-297.

15. Gaur A, Jewell DA, Liang Y, Ridzon D, Moore JH, Chen C, Ambros VR and Israel MA. Characterization of microRNA expression levels and their biological correlates in human cancer cell lines. Cancer Res. 2007; 67:2456-2468.

16. Xi Y, Nakajima G, Gavin E, Morris CG, Kudo K, Hayashi $\mathrm{K}$ and Ju J. Systematic analysis of microRNA expression of RNA extracted from fresh frozen and formalin-fixed paraffin-embedded samples. RNA. 2007; 13:1668-1674.

17. Lim LP, Lau NC, Garrett-Engele P, Grimson A, Schelter JM, Castle J, Bartel DP, Linsley PS and Johnson JM. Microarray analysis shows that some microRNAs downregulate large numbers of target mRNAs. Nature. 2005; 433:769-773. 
18. Liu CG, Calin GA, Meloon B, Gamliel N, Sevignani C, Ferracin M, Dumitru CD, Shimizu M, Zupo S, Dono M, Alder H, Bullrich F, Negrini M and Croce CM. An oligonucleotide microchip for genome-wide microRNA profiling in human and mouse tissues. Proc Natl Acad Sci U S A. 2004; 101:9740-9744.

19. Wang HJ, Ruan HJ, He XJ, Ma YY, Jiang XT, Xia YJ, Ye ZY and Tao HQ. MicroRNA-101 is down-regulated in gastric cancer and involved in cell migration and invasion. Eur J Cancer. 2010; 46:2295-2303.

20. Guo X, Guo L, Ji J, Zhang J, Chen X, Cai Q, Li J, Gu Q, Liu B, Zhu Z and Yu Y. miRNA-331-3p directly targets $\mathrm{E} 2 \mathrm{~F} 1$ and induces growth arrest in human gastric cancer. Biochem Biophys Res Commun. 2010; 398:1-6.

21. Ding L, Xu Y, Zhang W, Deng Y, Si M, Du Y, Yao H, Liu X, Ke Y, Si J and Zhou T. MiR-375 frequently downregulated in gastric cancer inhibits cell proliferation by targeting JAK2. Cell Res. 2010; 20:784-793.

22. Du Y, Xu Y, Ding L, Yao H, Yu H, Zhou T and Si J. Downregulation of miR-141 in gastric cancer and its involvement in cell growth. J Gastroenterol. 2009; 44:556-561.

23. Tie J, Pan Y, Zhao L, Wu K, Liu J, Sun S, Guo X, Wang B, Gang Y, Zhang Y, Li Q, Qiao T, Zhao Q, Nie Y and Fan D. MiR-218 inhibits invasion and metastasis of gastric cancer by targeting the Robo1 receptor. PLoS Genet. 2010; 6:e1000879.

24. Kim CH, Kim HK, Rettig RL, Kim J, Lee ET, Aprelikova O, Choi IJ, Munroe DJ and Green JE. miRNA signature associated with outcome of gastric cancer patients following chemotherapy. BMC Med Genomics. 2011; 4:79.

25. Craig VJ, Cogliatti SB, Rehrauer H, Wundisch T and Muller A. Epigenetic silencing of microRNA-203 dysregulates ABL1 expression and drives Helicobacter-associated gastric lymphomagenesis. Cancer Res. 2011; 71:3616-3624.

26. Yao Y, Suo AL, Li ZF, Liu LY, Tian T, Ni L, Zhang WG, Nan KJ, Song TS and Huang C. MicroRNA profiling of human gastric cancer. Mol Med Rep. 2009; 2:963-970.

27. Song F, Yang D, Liu B, Guo Y, Zheng H, Li L, Wang T, Yu J, Zhao Y, Niu R, Liang H, Winkler H, Zhang W, Hao $\mathrm{X}$ and Chen $\mathrm{K}$. Integrated microRNA network analyses identify a poor-prognosis subtype of gastric cancer characterized by the miR-200 family. Clin Cancer Res. 2014; 20:878-889.

28. Zhang X, Yan Z, Zhang J, Gong L, Li W, Cui J, Liu Y, Gao Z, Li J, Shen L and Lu Y. Combination of hsa-miR-375 and hsa-miR-142-5p as a predictor for recurrence risk in gastric cancer patients following surgical resection. Ann Oncol. 2011; 22:2257-2266.

29. Takei Y, Takigahira M, Mihara K, Tarumi Y and Yanagihara K. The metastasis-associated microRNA miR$516 a-3 p$ is a novel therapeutic target for inhibiting peritoneal dissemination of human scirrhous gastric cancer. Cancer Res. 2011; 71:1442-1453.
30. Tsukamoto Y, Nakada C, Noguchi T, Tanigawa M, Nguyen LT, Uchida T, Hijiya N, Matsuura K, Fujioka T, Seto M and Moriyama M. MicroRNA-375 is downregulated in gastric carcinomas and regulates cell survival by targeting PDK1 and 14-3-3zeta. Cancer Res. 2010; 70:2339-2349.

31. Bhattacharya R, Nicoloso M, Arvizo R, Wang E, Cortez A, Rossi S, Calin GA and Mukherjee P. MiR-15a and MiR-16 control Bmi-1 expression in ovarian cancer. Cancer Res. 2009; 69:9090-9095.

32. Dong P, Kaneuchi M, Watari H, Hamada J, Sudo S, Ju J and Sakuragi N. MicroRNA-194 inhibits epithelial to mesenchymal transition of endometrial cancer cells by targeting oncogene BMI-1. Mol Cancer. 2011; 10:99.

33. Shimono Y, Zabala M, Cho RW, Lobo N, Dalerba P, Qian D, Diehn M, Liu H, Panula SP, Chiao E, Dirbas FM, Somlo G, Pera RA, Lao K and Clarke MF. Downregulation of miRNA-200c links breast cancer stem cells with normal stem cells. Cell. 2009; 138:592-603.

34. Xiao G, Tang H, Wei W, Li J, Ji L and Ge J. Aberrant Expression of MicroRNA-15a and MicroRNA-16 Synergistically Associates with Tumor Progression and Prognosis in Patients with Colorectal Cancer. Gastroenterol Res Pract. 2014; 2014:364549.

35. Calin GA, Dumitru CD, Shimizu M, Bichi R, Zupo S, Noch E, Aldler H, Rattan S, Keating M, Rai K, Rassenti L, Kipps T, Negrini M, Bullrich F and Croce CM. Frequent deletions and down-regulation of micro- RNA genes miR15 and miR16 at 13q14 in chronic lymphocytic leukemia. Proc Natl Acad Sci U S A. 2002; 99:15524-15529.

36. Cimmino A, Calin GA, Fabbri M, Iorio MV, Ferracin M, Shimizu M, Wojcik SE, Aqeilan RI, Zupo S, Dono M, Rassenti L, Alder H, Volinia S, Liu CG, Kipps TJ, Negrini $\mathrm{M}$, et al. miR-15 and miR-16 induce apoptosis by targeting BCL2. Proc Natl Acad Sci U S A. 2005; 102:13944-13949.

37. Liu S, Tetzlaff MT, Cui R and Xu X. miR-200c inhibits melanoma progression and drug resistance through downregulation of BMI-1. Am J Pathol. 2012; 181:1823-1835.

38. Guo S, Xu X, Tang Y, Zhang C, Li J, Ouyang Y, Ju J, Bie P and Wang H. miR-15a inhibits cell proliferation and epithelial to mesenchymal transition in pancreatic ductal adenocarcinoma by down-regulating Bmi-1 expression. Cancer Lett. 2014; 344:40-46.

39. Yin $\mathrm{T}$, Wei H, Leng Z, Yang Z, Gou S, Wu H, Zhao G, $\mathrm{Hu} \mathrm{X}$ and Wang C. Bmi-1 promotes the chemoresistance, invasion and tumorigenesis of pancreatic cancer cells. Chemotherapy. 2011; 57:488-496.

40. Jacobs JJ, Kieboom K, Marino S, DePinho RA and van Lohuizen $\mathrm{M}$. The oncogene and Polycomb-group gene bmi-1 regulates cell proliferation and senescence through the ink4a locus. Nature. 1999; 397:164-168.

41. Wang Y, Guan Y, Wang F, Huang A, Wang S and Zhang YA. Bmi-1 regulates self-renewal, proliferation and senescence of human fetal neural stem cells in vitro. Neurosci Lett. 2010; 476:74-78. 
42. Guo BH, Feng Y, Zhang R, Xu LH, Li MZ, Kung HF, Song LB and Zeng MS. Bmi-1 promotes invasion and metastasis, and its elevated expression is correlated with an advanced stage of breast cancer. Mol Cancer. 2011; 10:10.

43. Dimri GP, Martinez JL, Jacobs JJ, Keblusek P, Itahana K, Van Lohuizen M, Campisi J, Wazer DE and Band V. The Bmi-1 oncogene induces telomerase activity and immortalizes human mammary epithelial cells. Cancer Res. 2002; 62:4736-4745.

44. van Lohuizen M, Verbeek S, Scheijen B, Wientjens E, van der Gulden $\mathrm{H}$ and Berns A. Identification of cooperating oncogenes in E mu-myc transgenic mice by provirus tagging. Cell. 1991; 65:737-752.

45. Simon JA and Kingston RE. Mechanisms of polycomb gene silencing: knowns and unknowns. Nat Rev Mol Cell Biol. 2009; 10:697-708.

46. Jacobs JJ, Scheijen B, Voncken JW, Kieboom K, Berns A and van Lohuizen M. Bmi-1 collaborates with c-Myc in tumorigenesis by inhibiting c-Myc-induced apoptosis via INK4a/ARF. Genes Dev. 1999; 13:2678-2690.

47. Zhang F, Sui L and Xin T. Correlations of BMI-1 expression and telomerase activity in ovarian cancer tissues. Exp Oncol. 2008; 30:70-74.

48. Jiang L, Wu J, Yang Y, Liu L, Song L, Li J and Li M. Bmi-1 promotes the aggressiveness of glioma via activating the NF-kappaB/MMP-9 signaling pathway. BMC Cancer. 2012; 12:406.

49. Silva J, Garcia V, Garcia JM, Pena C, Dominguez G, Diaz R, Lorenzo Y, Hurtado A, Sanchez A and Bonilla F. Circulating Bmi-1 mRNA as a possible prognostic factor for advanced breast cancer patients. Breast Cancer Res. 2007; 9:R55.

50. Xin T, Zhang FB, Sui GJ and Jin XM. Bmi-1 siRNA inhibited ovarian cancer cell line growth and decreased telomerase activity. Br J Biomed Sci. 2012; 69:62-66.
51. Wang Y, Zhe H, Ding Z, Gao P, Zhang N and Li G. Cancer stem cell marker Bmi-1 expression is associated with basallike phenotype and poor survival in breast cancer. World J Surg. 2012; 36:1189-1194.

52. Sempere LF, Preis M, Yezefski T, Ouyang H, Suriawinata AA, Silahtaroglu A, Conejo-Garcia JR, Kauppinen S, Wells W and Korc M. Fluorescence-based codetection with protein markers reveals distinct cellular compartments for altered MicroRNA expression in solid tumors. Clinical cancer research. 2010; 16:4246-4255.

53. Song LB, Li J, Liao WT, Feng Y, Yu CP, Hu LJ, Kong QL, Xu LH, Zhang X, Liu WL, Li MZ, Zhang L, Kang TB, Fu LW, Huang WL, Xia YF, et al. The polycomb group protein Bmi-1 represses the tumor suppressor PTEN and induces epithelial-mesenchymal transition in human nasopharyngeal epithelial cells. J Clin Invest. 2009; 119:3626-3636.

54. Choi YJ, Choi YL, Cho EY, Shin YK, Sung KW, Hwang YK, Lee SJ, Kong G, Lee JE, Kim JS, Kim JH, Yang JH and Nam SJ. Expression of Bmi-1 protein in tumor tissues is associated with favorable prognosis in breast cancer patients. Breast Cancer Res Treat. 2009; 113:83-93.

55. Kreso A, van Galen P, Pedley NM, Lima-Fernandes E, Frelin C, Davis T, Cao L, Baiazitov R, Du W, Sydorenko $\mathrm{N}$, Moon YC, Gibson L, Wang Y, Leung C, Iscove $\mathrm{NN}$, Arrowsmith $\mathrm{CH}$, et al. Self-renewal as a therapeutic target in human colorectal cancer. Nat Med. 2014; 20:29-36.

56. Park IK, Qian D, Kiel M, Becker MW, Pihalja M, Weissman IL, Morrison SJ and Clarke MF. Bmi-1 is required for maintenance of adult self-renewing haematopoietic stem cells. Nature. 2003; 423:302-305. 